\title{
Estimation of the economic burden of COVID-19 using Disability-Adjusted Life Years (DALYs) and Productivity Losses in Kerala, India: A model based analysis
}

\section{Denny John ( $\sim$ djohn1976@gmail.com )}

Amrita Institute of Medical Sciences and Research Centre, Amrita Vishwa Vidyapeetham, Kochi, Kerala, India https://orcid.org/0000-0002-4486-632X

\section{M.S. Narassima}

Amrita School of Engineering, Coimbatore, Amrita Vishwa Vidyapeetham, India https://orcid.org/00000002-4113-430X

\section{Jaideep C Menon}

Amrita Institute of Medical Sciences and Research Centre, Amrita Vishwa Vidyapeetham, Kochi, Kerala, India https://orcid.org/0000-0002-0786-8123

\section{Guru Rajesh Jammy}

Society for Health Allied Research and Education (SHARE-INDIA), Telangana, India. https://orcid.org/0000-0002-8579-6460

\section{Amitava Banerjee}

Institute of Health Informatics, University College London, London, UK

\section{Research Article}

Keywords: Burden of Disease, Disability-Adjusted Life Years (DALYs), Years of Potential Productive Life Lost (YPPLL), Cost of Productivity Lost (CPL), Kerala, India

Posted Date: August 19th, 2021

DOI: https://doi.org/10.21203/rs.3.rs-118146/v5

License: (c) (i) This work is licensed under a Creative Commons Attribution 4.0 International License. Read Full License 


\title{
Estimation of the economic burden of COVID-19 using Disability-Adjusted Life Years (DALYs) and Productivity Losses in Kerala, India: A model based analysis
}

\author{
Denny John ${ }^{1}$, M.S. Narassima², Jaideep C Menon ${ }^{3}$, Jammy Guru Rajesh ${ }^{4}$, Amitava Banerjee ${ }^{5}$ \\ Affiliations: \\ ${ }^{1}$ Department of Public Health, Amrita Institute of Medical Sciences and Research Centre, Amrita Vishwa Vidyapeetham, Kochi, Kerala, India \\ ${ }^{2}$ Department of Mechanical Engineering, Amrita School of Engineering, Coimbatore, Amrita Vishwa Vidyapeetham, India \\ ${ }^{3}$ Cardiology, Amrita Institute ofMedical Sciences and ResearchCentre, Kochi, Kerala, India \\ ${ }^{4}$ Society for Health, Allied Research and Education (SHARE-INDIA), Telangana, India \\ ${ }^{5}$ Farr Institute of HealthInformatics Research, UniversityCollege London, London, UK \\ Corresponding Author details: \\ Name: Denny John \\ Email: djohn1976@gmail.com
}

Address: Department of Public Health, Amrita Institute of Medical Sciences and Research Centre, Amrita Vishwa Vidyapeetham, Kochi, Kerala, India

\section{ABSTRACT}

Objectives: From the beginning of the COVID-19 pandemic, clinical practice and research, globally, have centered on the prevention of transmission and treatment of the disease. The pandemic has had a huge impact on the economy and stressed the healthcare systems worldwide. The present study estimates Disability-Adjusted Life Years (DALYs), Years of Potential Productive Life Lost (YPPLL), and Cost of Productivity Lost (CPL) due to premature mortality and absenteeism, secondary to COVID-19 in Kerala state, India.

Setting: Details on sociodemography, incidence, death, quarantine, recovery time, etc were derived from public sources and CODD-K for Kerala. The working proportion for 5-year age-gender cohorts and corresponding life expectancy were obtained from the Census of India 2011.

Primary and secondary outcome measures: The impact of disease was computed through model based analysis on various age-gender cohorts. Sensitivity Analysis has been conducted by adjusting six variables across 21 scenarios. We present two estimates, one till November 15, 2020, and later updated till June 10, 2021.

Results: Severity of infection and mortality were higher among the older cohorts, with males being more susceptible than females in most sub-groups. The DALYs for males and females were 15954.5 and 8638.4 till November 15, 2020, and 83853.0 and 56628.3 till June 10, 2021. The corresponding 
YPPLL were 1323.57 and 612.31 till November 15, 2020, and 6993.04 and 3811.57 till June 10, 2021 and CPL (premature mortality) were 263780579.94 and 41836001.82 till November 15, 2020, and 1419557903.76 and 278275495.29 till June 10, 2021.

Conclusions: Most of the COVID-19 disease burden was contributed by YLL. Losses due to YPPLL were reduced as the impact of COVID-19 infection was lesser among productive cohorts. CPL values for 40-49 year-olds were the highest. These estimates provide the data necessary for policymakers to work on, to reduce the economic burden of COVID-19 in Kerala.

\section{Article summary}

\section{Strengths and limitations of this study}

- The first study to characterize the economic burden caused by COVID-19 in Kerala state using DALYS, YPPLL, and CPL

- Use of public sourced data for analysis and presentation of results

- Exclusion of incidence of case post August 20, 2020, due to unavailability of data could lead to an underestimation of DALYS

- Psychological impacts of the mitigation strategies (e.g., lockdown, travel restrictions, etc.) that could increase mortality were not included in the scope

- Unpaid work and presenteeism data, and data on post-recovery illness and long-term effects of COVID-19 have not been considered.

\section{KEYWORDS}

Burden of Disease, Disability-Adjusted Life Years (DALYs), Years of Potential Productive Life Lost (YPPLL), Cost of Productivity Lost (CPL), Kerala, India 


\section{INTRODUCTION}

Since the first case of COVID-19 was reported in December 2019, COVID-19 has spread across all countries infecting $176,705,044$ people with 3,819,138 deaths and 160,737,654 recoveries worldwide as of June 14, 2021[1]. With lower access to quality health facilities in Low-and-MiddleIncome countries has placed a sizeable proportion at a higher risk[2]. India ranks second with $29,507,438$ cases and 28,148,977 recoveries as of June 14, 2021[1]. Higher infection rates have increased the burden on healthcare systems and thus increased the fatality rate[3].

Estimating the mortality due to COVID-19 helps to understand the dynamics of the pandemic. The role of socio-demographics, social determinants, and geography is important to assess the differential risk levels to the disease with age, gender, and geography[4]. However, indirect effects due to morbidity and post-COVID-19 syndromes have highlighted the far-reaching consequences of the pandemic [5]. Also, Social Determinants of Health (SDH) often create inequalities between and within territories disproportionately such as losses incurred by the caregivers of the infected, frontline workers, food insecurity, work-life conditions, unemployment, etc., that have a considerable impact on public and health systems[6]. Governments have imposed strict measures to curtail the morbidity and mortality caused by COVID-19. Individual-level measures such as selfisolation and social distancing and population-level measures like lockdowns are widely adopted to limit spread[2,7,8]. The SDH plays a vital role in strategizing the interventions especially in LMICs where there are differences in socioeconomic strata [6]. Quantifying the health and economic impact of COVID-19 would be a reflection of the policy decisions taken[9]. Economic impact assessment is highly important in countries/territories like India and states such as Kerala where most of the infected people have recovered.

In India, the first case of COVID-19 was reported in Kerala on January 30, 2020. Timely interventions such as contact tracing, testing, quarantine, isolation, and treatment had reduced the spread of the disease in Kerala[10]. The number of cases in Kerala has now reached 2,728,239 with 11,181 deaths and $2,593,625$ recoveries as of June 13,2021 . The resulting economic burden of COVID-19 in the state thus appears to be substantial. Therefore, this present study aimed to estimate economic burden and productivity loss using Disability-Adjusted Life Years (DALYs), Years of Potential Productive Life Lost (YPPLL), and Cost of Productivity Lost (CPL)and their effects on age and gender for the state of Kerala. 


\section{METHODS}

\section{Data Collection}

The present work is an age-gender cohort-based observational study to estimate the DALYs and productivity losses due to COVID-19 in Kerala, India. The effect of multimorbidity has been considered to compute the Burden of Disease (BoD). Human Capital Approach has been adopted to estimate productivity losses. Publicly available data from various sources have been used to gather sociodemographic details, information about the incidence, death due to COVID-19, information on quarantine, per capita income, etc., for the state of Kerala[11-13]. The first reported case of COVID19 in Kerala dates back to January 30, 2020, from when the estimates for the present study have been collected[12,13].

The 5-year age-gender population of Kerala, working population in each age-gender cohort, and the corresponding life expectancies were obtained from the 2011 Census of India[11]. Incidence data documented by Team Collective for Open Data Distribution-Keralam (CODD-K) was till August 20, 2020, was used to classify the incidence of the age-gender cohort (Table S I). Out of 52,199 reported cases till August 20, 2020, data of 7645 patients were excluded as they did not contain information on age and gender[12]. Recovery time documented by the team for 1,012 patients in Kerala was used from CODD-K [12]. Data for the number of deaths were extracted from the Government of Kerala dashboard and CODD-K $[12,13]$. The infections were categorized as mild, moderate, and severe/ critical[13,14]. Further, estimates updated till 2021 have also been presented throughout all of which will hereon be indicated using a subscript '2021'. Table I presents the information on various parameters used for the study.

Table I: Parameters used for the study.

\begin{tabular}{|c|c|c|c|c|}
\hline \multirow{2}{*}{ Parameters } & \multicolumn{2}{|r|}{ Values } & \multirow{2}{*}{ Reference } & \multirow{2}{*}{ Till Date } \\
\hline & Value & Sensitivity Analysis (SA)* & & \\
\hline \multicolumn{2}{|c|}{ Number of cases } & \multirow{3}{*}{$\begin{array}{l}10 \%(\mathrm{~S} 12), 20 \%(\mathrm{~S} 13) \text { and } 30 \%(\mathrm{~S} 14) \\
\text { increase in infected cases }\end{array}$} & \multirow{3}{*}[3,12]{} & \multirow{3}{*}{$\begin{array}{l}20-\text { Aug- } \\
20\end{array}$} \\
\hline Actual & 52199 & & & \\
\hline Valid records & 44554 & & & \\
\hline \multicolumn{2}{|c|}{ Number of deaths } & \multirow{3}{*}{$\begin{array}{l}10 \%(\mathrm{~S} 18), 20 \%(\mathrm{~S} 19) \text { and } 30 \%(\mathrm{~S} 20) \\
\text { increase in deaths }\end{array}$} & \multirow{3}{*}[3,12,13]{} & \multirow{3}{*}{$\begin{array}{l}\text { 10-Jun- } \\
2021\end{array}$} \\
\hline Actual & 1869 & & & \\
\hline Valid records & 1841 & & & \\
\hline \multicolumn{2}{|c|}{ Quarantine } & $10 \%(\mathrm{~S} 15), 20 \%(\mathrm{~S} 16)$ and $30 \%$ (S17) & \multirow{2}{*}[12,13]{} & 29-Aug- \\
\hline Home (Mild cases) & 158543 & increase in mild cases & & 20 \\
\hline
\end{tabular}




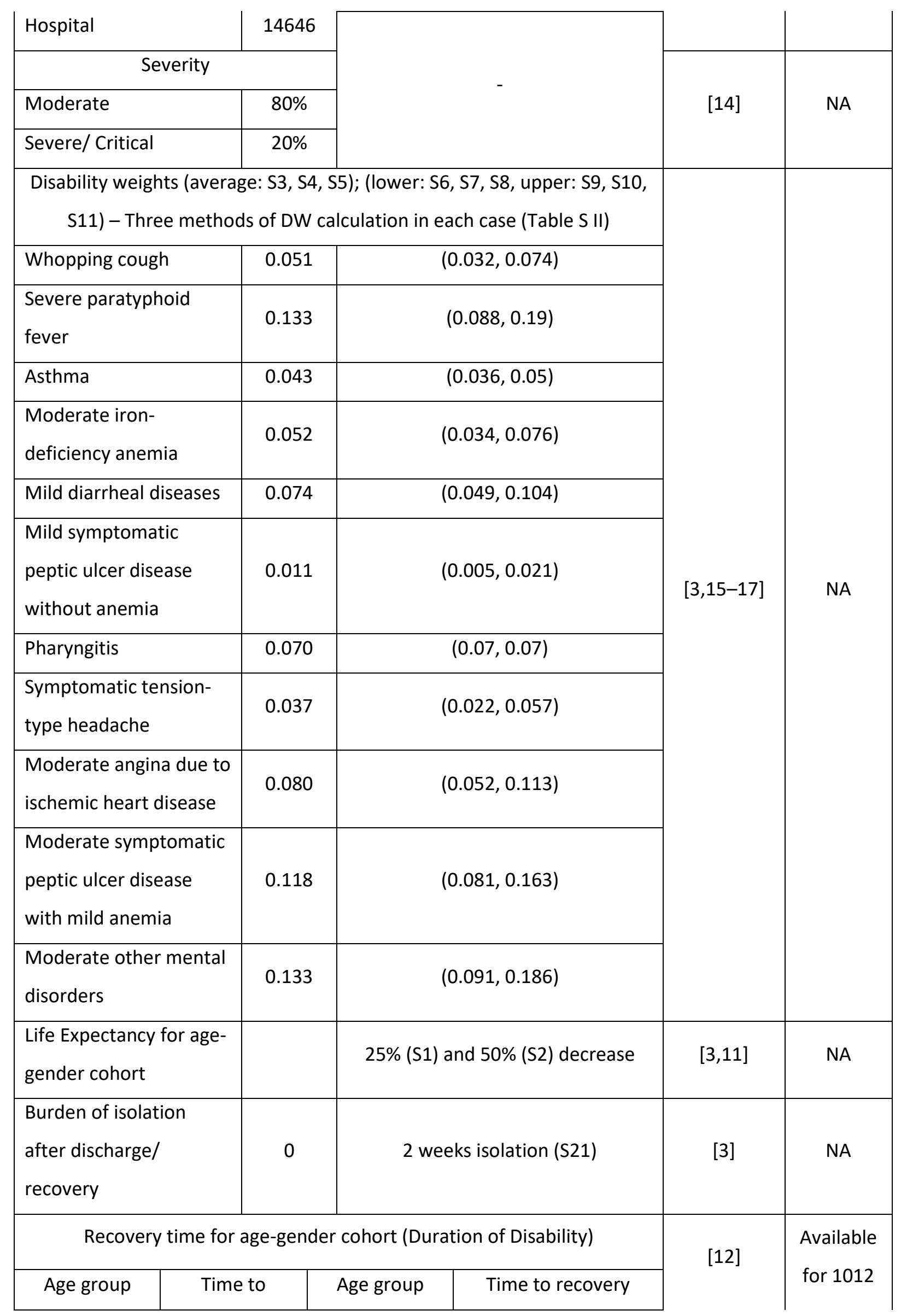




\begin{tabular}{|c|c|c|c|c|c|}
\hline & $\begin{array}{c}\text { recovery } \\
\text { (days) }\end{array}$ & & (days) & & patients \\
\hline 0 to 1 & 13.00 & 45 to 50 & 13.49 & & \\
\hline 1 to 5 & 17.55 & 50 to 55 & 15.55 & & \\
\hline 5 to 10 & 14.40 & 55 to 60 & 13.57 & & \\
\hline 10 to 15 & 15.59 & 60 to 65 & 13.61 & & \\
\hline 15 to 20 & 13.94 & 65 to 70 & 18.94 & & \\
\hline 20 to 25 & 13.82 & 70 to 75 & 15.00 & & \\
\hline 25 to 30 & 13.16 & 75 to 80 & 11.57 & & \\
\hline 30 to 35 & 14.07 & 80 to 85 & 15.00 & & \\
\hline 35 to 40 & 13.54 & \multirow{2}{*}{$85+$} & \multirow{2}{*}{17.33} & & \\
\hline 40 to 45 & 15.26 & & & & \\
\hline \multicolumn{4}{|c|}{ Life expectancy at age of death (L) } & \multirow{21}{*}[11]{} & \multirow{21}{*}{ NA } \\
\hline \multicolumn{2}{|l|}{ Age } & Male & Female & & \\
\hline \multicolumn{2}{|l|}{0 to 1} & 72.5 & 77.9 & & \\
\hline \multicolumn{2}{|l|}{1 to 5} & 72.3 & 77.8 & & \\
\hline \multicolumn{2}{|l|}{5 to 10} & 68.4 & 73.9 & & \\
\hline \multicolumn{2}{|l|}{10 to 15} & 63.4 & 69.0 & & \\
\hline \multicolumn{2}{|l|}{15 to 20} & 58.6 & 64.1 & & \\
\hline \multicolumn{2}{|l|}{20 to 25} & 53.7 & 59.2 & & \\
\hline \multicolumn{2}{|l|}{25 to 30} & 48.9 & 54.4 & & \\
\hline \multicolumn{2}{|l|}{30 to 35} & 44.2 & 49.5 & & \\
\hline \multicolumn{2}{|l|}{35 to 40} & 39.5 & 44.7 & & \\
\hline \multicolumn{2}{|l|}{40 to 45} & 34.8 & 39.9 & & \\
\hline \multicolumn{2}{|l|}{45 to 50} & 30.3 & 35.1 & & \\
\hline \multicolumn{2}{|l|}{50 to 55} & 25.9 & 30.5 & & \\
\hline \multicolumn{2}{|l|}{55 to 60} & 21.8 & 26.2 & & \\
\hline \multicolumn{2}{|l|}{60 to 65} & 17.9 & 21.9 & & \\
\hline \multicolumn{2}{|l|}{65 to 70} & 14.3 & 17.9 & & \\
\hline \multicolumn{2}{|l|}{70 to 75} & 11.4 & 14.3 & & \\
\hline \multicolumn{2}{|l|}{75 to 80} & 8.6 & 11.0 & & \\
\hline \multicolumn{2}{|l|}{80 to 85} & 6.2 & 7.9 & & \\
\hline \multicolumn{2}{|l|}{$85+$} & 4.5 & 5.6 & & \\
\hline
\end{tabular}




\begin{tabular}{|c|c|c|c|c|}
\hline $\begin{array}{l}\text { Discount rate for value } \\
\text { of life }\end{array}$ & $2.90 \%$ & - & [18] & NA \\
\hline Age-gender population & \multirow{2}{*}{$\begin{array}{c}\text { Table S } \\
\text { III }\end{array}$} & \multirow[b]{2}{*}{-} & \multirow[b]{2}{*}{ [11] } & \multirow[b]{2}{*}{ NA } \\
\hline $\begin{array}{l}\text { Age-gender working } \\
\text { population }\end{array}$ & & & & \\
\hline $\begin{array}{l}\text { Discount rate (Financial } \\
\text { Benchmark) }\end{array}$ & $4.25 \%$ & - & [19] & 6-Nov-20 \\
\hline $\begin{array}{l}\text { Stay in Intensive Care } \\
\text { Unit (ICU) }\end{array}$ & 8 days & - & {$[20,21]$} & NA \\
\hline $\begin{array}{l}\text { Retirement age in } \\
\text { Kerala (years) }\end{array}$ & 56 & - & {$[22]$} & NA \\
\hline $\begin{array}{l}\text { Number of working } \\
\text { days in a week }\end{array}$ & 6 & - & [23] & NA \\
\hline $\begin{array}{l}\text { Per capita Gross } \\
\text { Domestic Product (GDP) } \\
\text { in Kerala }\end{array}$ & $\begin{array}{l}\text { 221904I } \\
\text { NR/ year }\end{array}$ & - & [24] & 2020 \\
\hline
\end{tabular}

*- Scenarios of Sensitivity Analysis have been denoted from S1 to S21. A detailed description is provided in table S IV

\section{Estimation of the distribution of cases till June 10, 2021}

The distribution of cases for age-gender cohorts in Kerala in 2020 and India in 2020 \& 2021 was used to estimate the distribution of cases in Kerala till June 10, 2021 (Table S I). The rationale behind the method is that the percentage deviations in distribution of cases for each age-gender cohort in India then (2020) and now (2021) and those of Kerala are assumed to be the same. In this way, the distribution of cases for age-gender cohorts has been computed till June 10, 2021 (Table S V). The actual cases in Kerala as of June 10,2021, is 2,688,590 while our estimates cumulate to 2,688,516 with an error of $0.0028 \%$.

\section{Disability-Adjusted Life Year (DALY)}

DALYs are standard measures to estimate the burden of disease in public health and are calculated as the sum of Years Lived with Disability (YLD) and Years of life lost (YLL) $[3,9,25]$. DALYs take into account the disability caused by the disease (YLD) and the premature mortality (YLL)[9]. Determining YLLs, YLDs and DALYs would allow us to measure the shortfall of the deceased and life years lost. YLLs explain the loss incurred as a result of death due to an event by comparing it with the years that 
they would have lived otherwise. YLLs become high in case of either higher mortality or mortality of younger people or both[4]. Years of Potential Productive Life Lost (YPPLL) and Cost of Productivity Lost (CPL) are widely adopted measures that majorly explain the economic burden due to an event[26].

DALYs were calculated using an incidence-based approach[3,18]. DALY estimates were obtained for the age-gender split to identify the more vulnerable groups[9]. Though incidence-based approaches do not consider the severity of diseases, owing to the diverse impact of COVID-19, severity was considered to assign the Disability Weights (DW)[3]. Initial estimates of YLDs are presented only till August 20, 2020, DALYs estimated in this study are certainly an underestimation. However, YLDs contribute only a minor share to the DALY estimates[3,9,27]. Discounting for the value of life (discount rate of $2.9 \%$ ) was used in the calculation of DALYs[18]. DALYs with no discounting have also been presented in table II. DWs were chosen based on the symptoms experienced by patients and were varied based on the severity of infection. The proportion of home quarantine cases were considered to be mild, whilst the proportion of hospitalized cases was further split into moderate and critical (table I). The symptoms, proportion of people experiencing each symptom, and corresponding DWs are presented in table $\mathrm{S} \|[28]$.

$Y L D=\frac{I * D W * D\left(1-e^{-r D}\right)}{r}$

where $r$ = discount rate; $D=$ disability duration (years); $I$ = number of incident cases

$Y L L=\frac{N}{r}\left(1-e^{-r L}\right)$

where $L=$ life expectancy at age of death (years); $N=$ number of deaths.

$D A L Y=Y L L+Y L D$

Most of the BoDstudies do not consider multimorbidity, which might produce inaccurate estimates[25]. Three methods for calculation of Combined Disability Weights (CDW) for multimorbidity as reported by Hilderlink et al (2016) viz. additive, multiplicative, and maximum limit methods, were employed in this study[25].

$$
\begin{aligned}
& D w_{i j}=D W_{i}+D W_{j} \\
& D W_{i j}=1-\left(1-D W_{i}\right) *\left(1-D w_{j}\right) \\
& D W_{i j}=\max \left(D W_{i}, D W_{j}\right)
\end{aligned}
$$

where ' $i$ ' and ' $j$ ' indicate the DWs of ' ${ }^{\prime}{ }^{\prime \text { th }}$ and ' $j$ 'th disabilities. 


\section{Productivity Losses (YPPLL and CPL)}

YPPLL defines the number of productive years an average person would have lived otherwise. The working population proportion of each cohort was multiplied with the YPPLL to estimate the CPL lost due to morbidity and absenteeism. Recovery days for the severe cases were extended by 8 days to account for the ICU stay. Productivity losses were estimated using the Human Capital Approach considering absenteeism and premature mortality for temporary and permanent losses respectively[9,29]. For calculation of productivity losses, people from age groups 15 to 60 were chosen considering the employment age[30] and retirement age of Kerala[22]. [18,31].

YPPLL $=\sum_{i=1}^{n} D_{i} * w_{i} * d \quad \mid i=1,2, \ldots, n$

where ' $i$ ' represents ' $n$ ' age-gender cohorts; $D_{i}=$ deaths at age; $w_{i}=$ productive years remaining at age of death (years); $d$ = discount rate for the value of life as proposed by Reserve Bank of India (RBI)[19]. were selected[19]. These are applicable for every year excluding the first year[32]. CPL for premature mortality and absenteeism was computed as shown in Eqn. (8) and (9).

$C P L=\sum_{j=1}^{J} Y P P L L_{j} *$ per capita $G D P * P$

$C P L_{\text {absenteeism }}=\sum_{j=1}^{J} S * L_{j} * N * P$

where $S$ = average salary per day considering the number of paid working days per week as six; $L_{j}=$ average recovery time; $\mathrm{N}=$ Number of incident cases; $\mathrm{P}=$ proportion of the working population, in cohort ' $j$ '. For the computation of productivity losses, the proportion of the working population was considered along with an extended disability period for severe cases to account for the ICU stay[20,21].

\section{Sensitivity Analysis (SA)}

A spectrum of scenarios (table S IV) was considered to analyze the effect of each parameter on the DALY estimates. The key idea of performing SA is to assist policymakers to anticipate the effects brought in by each of the driving variables. As most of the deceased cases had underlying health conditions that reduce the life expectancy, Scenario 1 (S1) and Scenario 2 (S2) have been developed[4,33]. Increasing the number of mild cases, overall cases and deaths are conservative analyses to help the healthcare fraternity and policymakers[3].

\section{Validation}

To ensure credibility, the data related to COVID-19 (Table I) were collected from various official sources, reports, and published works $[3,11-17,20,21]$. Discount rates for the Financial Benchmark 
and the value of life were taken into account on the values defined by the Reserve Bank of India [19] and Shanmugam (2011) [18] respectively. For the computation of the DALY, three different approaches to calculate the CDW as mentioned by Hilderink et al (2016) were used [25]. The DALY estimates and productivity losses were computed as done by Wyper et al. (2020) [34]and Rumisha et al. (2020)[35].

\section{Patient and public involvement}

The data used for inputs and analysis were derived from public sources (such as websites) and published literature. Our research question for estimating economic burden and productivity loss in Kerala was aimed based on the rise in the number of cases in Kerala from July to November 2020. The increase in the number of cases would also mean the increased productivity losses due to COVID-19 for patients and their family members especially those who died or were hospitalised due to COVID-19. However, as our model based analysis used data from published sources such as publications, and websites, and modeling methods, patients and/or the public were not involved in the design, or conduct, or reporting, or dissemination plans of the research.

\section{Cohort description}

From July 2020 to June 2021 there was a significant rise in the number of COVID-19 cases in Kerala. The increase in the number of cases would also mean increased economic loss due to COVID-19 for patients and their family members, mainly due to the rise in hospitalisations and deaths. We did not involve any patients in the design of this study as we used publicly available sources. However, we aim to disseminate the findings of this paper through various media channels post-publication to reach out to policymakers and the general public in the state of Kerala.

\section{RESULTS}

From the distribution of cases and deaths (figure S1 (till Nov 15, 2020), S2 (till June 10, 2021)), it is clear that older adults are disproportionately vulnerable to be severely affected by the disease. Though the age group of 25 to 30 males and females account for $13.45 \%$ and $11.06 \%$ of the total number of cases, their proportionate mortality remains as low as $0.80 \%$ and $1.17 \%$ respectively (figure S1). Contrastingly, while the male and female proportion of cases for the age group 65 to 70 is only $2.11 \%$ and $2.75 \%$ of the overall cases, their proportionate mortality remains as high as $17.88 \%$ and $13.13 \%$ respectively (figure S1). The 2021 estimates confirm that the elderly people from age groups 55 to 70 (figure S2) are affected high as their proportionate mortality is $39.99 \%$ though their proportionate incidence is as low as $12.34 \%$. 
DALY estimates calculated using the average DW scores using the additive method were considered as the baseline scenario for Sensitivity Analysis (SA). From table S VI, it is clear that the YLL is the major proportion of DALYs (Discounted), with Male and Female YLL and YLL2021 of age group 60 to 65 cumulating to $16.58 \%$ \& $16.46 \%$ and $16.21 \%$ \& $15.43 \%$ respectively. Since the cohort does not fall into the productive population (considering the employment age), these might not impact the productivity losses. Considering the YLLs and DALYs in the productive population, the YLLs and DALYs of males and females are the highest for the age group 55 to 60 . Comparing the discounted and undiscounted DALYs, we see that the undiscounted DALY and DALY 2021 of males and females are $36.02 \% \& 44.15 \%$ and $33.1 \%$ and $38.52 \%$ higher than those of the discounted ones. The discount rate for the value of life was considered as $2.90 \%$ for all the scenarios in the study [18]. Also, the DALYs per million and DALY 2021 per million were estimated to be 709.2 and 4050.99 based on the projected population of Kerala for the year 2020 which is $34,678,294[36]$.

Table II: DALY estimates for the baseline scenario (S3)

\begin{tabular}{|c|c|c|c|c|c|c|c|c|}
\hline \multirow{3}{*}{ Age } & \multicolumn{4}{|c|}{ DALYs till Nov 15, 2020} & \multicolumn{4}{|c|}{ DALYs till June 10, 2021} \\
\hline & \multicolumn{2}{|c|}{ Discounted } & \multicolumn{2}{|c|}{ Undiscounted } & \multicolumn{2}{|c|}{ Discounted } & \multicolumn{2}{|c|}{ Undiscounted } \\
\hline & M & $\mathbf{F}$ & M & $\mathbf{F}$ & M & $\mathbf{F}$ & M & $\mathbf{F}$ \\
\hline 0 to 1 & 30.3 & 61.8 & 72.6 & 155.9 & 63.7 & 64.8 & 145.1 & 155.9 \\
\hline 1 to 5 & 0.4 & 0.4 & 0.4 & 0.4 & 50.7 & 19.7 & 72.7 & 0.4 \\
\hline 5 to 10 & 0.3 & 0.3 & 0.3 & 0.3 & 47.4 & 15.5 & 68.7 & 0.3 \\
\hline 10 to 15 & 58.4 & 30.1 & 127.2 & 69.3 & 114.1 & 80.5 & 190.6 & 138.3 \\
\hline 15 to 20 & 57.0 & 58.6 & 117.8 & 128.6 & 265.0 & 200.8 & 469.4 & 385.0 \\
\hline 20 to 25 & 137.3 & 113.8 & 269.7 & 237.5 & 590.7 & 465.0 & 1021.5 & 888.7 \\
\hline 25 to 30 & 262.7 & 192.2 & 490.4 & 381.4 & 893.3 & 639.8 & 1517.3 & 1197.4 \\
\hline 30 to 35 & 126.0 & 132.0 & 222.4 & 248.1 & 1583.7 & 1168.2 & 2653.4 & 2129.1 \\
\hline 35 to 40 & 636.2 & 351.3 & 1067.8 & 626.3 & 3581.9 & 1862.3 & 5886.8 & 3263.6 \\
\hline 40 to 45 & 899.7 & 189.7 & 1428.1 & 319.8 & 5050.7 & 2306.4 & 7900.9 & 3831.0 \\
\hline 45 to 50 & 1150.2 & 507.0 & 1728.1 & 807.8 & 6874.1 & 4193.9 & 10242.4 & 6634.4 \\
\hline 50 to 55 & 1603.7 & 952.0 & 2280.2 & 1434.0 & 9240.0 & 5943.5 & 13054.6 & 8906.5 \\
\hline 55 to 60 & 2343.5 & 1413.5 & 3161.6 & 2017.8 & 11231.3 & 8078.1 & 15108.0 & 11502.2 \\
\hline 60 to 65 & 2639.5 & 1426.8 & 3383.5 & 1927.5 & 13502.1 & 8690.6 & 17273.9 & 11716.8 \\
\hline 65 to 70 & 2610.8 & 1089.5 & 3189.4 & 1396.5 & 11711.3 & 7826.5 & 14271.9 & 10006.4 \\
\hline 70 to 75 & 1669.8 & 983.4 & 1961.0 & 1201.3 & 9513.7 & 6775.0 & 11160.8 & 8265.5 \\
\hline 75 to 80 & 898.2 & 508.6 & 1014.8 & 594.0 & 5201.8 & 4080.8 & 5873.8 & 4763.0 \\
\hline 80 to 85 & 556.2 & 430.7 & 607.6 & 482.0 & 2908.8 & 2637.2 & 3174.4 & 2946.8 \\
\hline $85+$ & 274.3 & 196.5 & 292.5 & 212.8 & 1428.5 & 1579.8 & 1521.0 & 1708.0 \\
\hline Total & 15954.5 & 8638.4 & 21415.5 & 12241.5 & 83853.0 & 56628.3 & 111607.3 & 78439.5 \\
\hline
\end{tabular}

Figure S3 a) to i) and figure $\mathrm{S} 4 \mathrm{a}$ ) to i) show that on the whole, the DALYs for males are higher than those of females except for the age groups 30 to 35,15 to 20 , and less than 10 . About $47.69 \%$ and $45.34 \%$ of overall DALYs, and $43.46 \%$ and $43.43 \%$ of the overall DALY ${ }_{2021}$ for males and females 
respectively are from the age groups 55 to 70 . It is highly disproportionate as the number of cases from these age groups piles up to only $11.13 \%$ and $13.11 \%$ (2020), and $11.32 \%$ and $13.37 \%$ (2021) of cases for males and females respectively. Figure S3 and figure S4 present the DALYs calculated for the nine different scenarios (refer Table S II) that involve altering the DW calculation methods and values.

To measure the impact of the disease on the productivity of the state, YPPLL and CPL were calculated among the productive age group of $15-60$ years. The age group $25-49$ being the majority is the prime contributor to productivity. Fortunately, there is a relatively lesser impact of the infection in terms of duration of illness and mortality for these age groups, which has reduced the losses to some extent (Table III). Recovery days mentioned in table S III are exclusive of the ICU stay of severe cases.

Table III shows that the CPL values for people aged from $40-49$ years were the highest, and constituted about $51.34 \%$ and $41.76 \%$ of the total CPL values (for premature mortality) of males and females respectively. CPL values for absenteeism are also the highest for the same age cohort for both males and females accounting for up to $26.53 \%$ and $31.35 \%$ respectively. $\mathrm{CPL}_{2021}$ (for premature mortality) gets the highest shares of $58.98 \%$ and $58.73 \%$ from male and female cohorts of the $41-50$ age group (Table IV). Similarly, $\mathrm{CPL}_{2021}$ has a maximum of $25.89 \%$ and $30.96 \%$ from the same cohorts respectively.

Table III: YPPLL, CPL (Mortality and Absenteeism) till November 15, 2020

\begin{tabular}{|l|l|l|l|l|l|l|}
\hline $\begin{array}{l}\text { Age- } \\
\text { Group }\end{array}$ & $\begin{array}{l}\text { Pears of Potential } \\
\text { Productive Life Lost } \\
\text { (YPPL) }\end{array}$ & \multicolumn{2}{|c|}{$\begin{array}{r}\text { Cost of Productivity Lost (CPL) - } \\
\text { Death }\end{array}$} & \multicolumn{2}{c|}{$\begin{array}{c}\text { Cost of Productivity Lost (CPL) - } \\
\text { Morbidity }\end{array}$} \\
\hline & Males & Females & Males & Females & Males & Females \\
\hline $15-19$ & 8.02 & 16.04 & $200,004.28$ & $144,074.81$ & $1,308,538.75$ & $325,006.38$ \\
\hline $20-24$ & 43.05 & 25.83 & $5,009,096.46$ & $849,735.38$ & $13,824,381.71$ & $2,252,069.57$ \\
\hline $25-29$ & 81.38 & 54.25 & $15,385,047.11$ & $2,675,078.71$ & $28,999,248.30$ & $3,130,470.52$ \\
\hline $30-34$ & 46.07 & 46.07 & $9,543,101.81$ & $2,934,692.41$ & $32,044,805.25$ & $4,055,127.61$ \\
\hline $35-39$ & 197.61 & 107.79 & $41,717,765.16$ & $8,623,040.56$ & $28,976,931.25$ & $4,149,430.14$ \\
\hline $40-49$ & 646.28 & 215.43 & $135,448,141.17$ & $17,470,735.95$ & $48,999,357.83$ & $9,131,773.54$ \\
\hline $50-59$ & 301.17 & 146.91 & $56,477,423.96$ & $9,138,644.00$ & $30,872,800.27$ & $6,134,611.07$ \\
\hline Total & & & $263,780,579.94$ & $41,836,001.82$ & $185,026,063.37$ & $29,178,488.82$ \\
\hline
\end{tabular}

Table IV: YPPLL, CPL (Mortality and Absenteeism) till June 10, 2021 (Refer Table S VII for incidence and deaths)

\begin{tabular}{|l|l|l|l|l|l|l|}
\hline $\begin{array}{l}\text { Age- } \\
\text { Group }\end{array}$ & $\begin{array}{c}|c| \\
\begin{array}{c}\text { Years of Potential } \\
\text { Productive Life Lost } \\
\text { (YPPLL) }\end{array}\end{array}$ & \multicolumn{2}{|c|}{$\begin{array}{c}\text { Cost of Productivity Lost (CPL) - } \\
\text { Death }\end{array}$} & \multicolumn{2}{c|}{$\begin{array}{c}\text { Cost of Productivity Lost (CPL) - } \\
\text { Morbidity }\end{array}$} \\
\hline & Males & Females & Males & Females & Males & Females \\
\hline $16-20$ & 65.17 & 48.88 & $1,625,265.52$ & $439,040.27$ & $102,297,314.03$ & $23,652,339.15$ \\
\hline
\end{tabular}




\begin{tabular}{|l|l|l|l|l|l|l|}
$21-25$ & 165.51 & 130.67 & $19,259,902.22$ & $4,298,973.72$ & $886,623,358.12$ & $140,085,916.15$ \\
\hline $26-30$ & 282.14 & 200.23 & $53,340,135.18$ & $9,872,885.34$ & $1,831,188,038.59$ & $187,207,907.26$ \\
\hline $31-35$ & 552.34 & 395.84 & $114,409,861.84$ & $25,214,693.78$ & $1,875,906,232.92$ & $243,394,778.33$ \\
\hline $36-40$ & 1321.80 & 647.59 & $279,048,434.48$ & $51,808,021.93$ & $1,788,669,340.39$ & $262,987,085.64$ \\
\hline $41-50$ & 3994.98 & 2015.17 & $837,278,167.58$ & $163,427,668.31$ & $2,860,063,434.24$ & $541,756,862.03$ \\
\hline $51-59$ & 611.09 & 373.19 & $114,596,136.95$ & $23,214,211.95$ & $1,703,001,999.97$ & $350,660,556.84$ \\
\hline Total & & $1,419,557,903.76$ & $278,275,495.29$ & $11,047,749,718.26$ & $1,749,745,445.40$ \\
\hline
\end{tabular}

\section{SENSITIVITY ANALYSIS (SA)}

Figure 1 a) to e) and $1 \mathrm{f}$ ) present SA explaining the role of each variable to economic burden to provide a better interpretation of the changes and comparison of the DALY estimates across all the scenarios for 2020. Figure 2 a) to e) and 2 f) present similar results for 2021 estimates. From figure 1 a) it is evident that the reduction in life expectancy by $25 \%$ and $50 \%$ reduced the DALYs by $19.7 \%$ and $42.47 \%$ for males and $18.78 \%$ and $41.08 \%$ for females respectively. Likewise, DALY 2021 reduced by $19.53 \%$ and $42.11 \%$ for males and $18.89 \%$ and $41.17 \%$ for females respectively (figure $2 a$ )). For figure 1 b), c) and e), and figure 2 b), c) and e), only YLDs were compared as the variables adjusted in these scenarios do not alter the YLLs. Comparing the DALY estimates might not explain the effect of variables clearly. For figure 1 a) and d), and figure 2 a) and d) the DALY estimates were directly compared. Increasing the overall cases by $10 \%, 20 \%$, and 30\% increased the YLDs proportionately equal to the percentage increase in the number of cases. An increase in the mild cases by $10 \%, 20 \%$, and $30 \%$ increased the YLDs by $9.15 \%, 18.31 \%$, and $27.46 \%$ respectively for both male and female cohorts. An increase in deaths by $10 \%, 20 \%$, and $30 \%$ increased the DALYs by $9.91 \%, 19.91 \%$, and $29.9 \%$ respectively for both male and female cohorts. The increase of the burden of isolation of two weeks increased the YLDs from 12.24 to 48.01 for males and from 6.88 to 26.74 for females, and YLD 2021 from 738.82 to 2897.92 for male and from 414.90 to 1612.10 for females.

\section{<INSERT FIGURE 1> \\ <INSERT FIGURE 2>}

Three different approaches for average, lower and upper limit values of DW have been used to arrive at YLDs. DALYs are seen to be the highest when the number of deaths is altered. The DALYs increase by $29.9 \%$ from that of S3 for both cohorts when the number of deaths increases by $30 \%$. These values would be still higher if the mortality among younger cohorts is high owing to their longer life expectancy during the age of death. 


\section{DISCUSSION}

\section{Main findings of this study}

In this study, for the baseline scenario, YLLs were 15942.3 and 8631.6 and the YLDs were 12.2 and 6.9 for males and females. Also, YLL Y2021 $_{1}$ were 83114.1 and 56213.4 and the YLD $_{2021}$ were 738.8 and 414.9 for males and females. DALYs and DALY 2021 were estimated as 709.2 per million and 4050.99 per million population based on the year 2020 population projections [36]. However, the DALY estimate will be impacted by the quality of the data reported. Based on an article published by the BBC, deaths due to COVID-19 as estimated by the volunteers are 3,356 which is $70.44 \%$ higher than the officially reported count 1969 as of November 19, 2020[13,37]. Considering the effect of asymptomatic cases that act as latent spreaders, DWs due to presenteeism, and unpaid work could increase the losses [38]. These facts are concerning as the actual DALYs might be way higher than those estimated using official figures.

The DALY 2021 estimates sum up to 83853 and 56628.3 for males and females respectively indicating a very high impact of the pandemic. The $\mathrm{YLL}_{2021}$ were computed to be 83114.1 and 56213.4 for male and female with $\mathrm{YLD}_{2021}$ are only 738.8 and 414.9 for male and female. Reports state that the second wave has affected the younger population significantly, unlike the first. The distribution of cases among age groups 21-30, 31-40, and 41-50 till May 31, 2021 are 2,61,232, 2,52,935, and 2,33,126 people respectively. Also, 18\% of the people who died during April and May 2021 in the state were not co-morbid[39].

In addition, the productivity losses in terms of YPPLL and CPL for mortality and absenteeism for the productive population (15 to 60 years of age) were estimated. Multimorbidity was taken into account for the calculation of CDW. CPL values (for premature mortality) for a younger population less than 25 years of age just $1.97 \%$ and $2.37 \%$ for males and females respectively. Likewise, $\mathrm{CPL}_{2021}$ (premature mortality) for the same cohorts constitute $1.47 \%$ and $1.70 \%$ respectively. This is because of the lesser proportion of people working in this age group and also the lesser impact of the disease in terms of mortality. Considering the CPL due to absenteeism, the values for younger people less than 25 years of age are $8.16 \%$ and $8.83 \%$ for males and females respectively. A similar trend is observed in $\mathrm{CPL}_{2021}$ due to absenteeism with $8.95 \%$ and $9.36 \%$ contribution from males and females less than 25 years of age. This is higher compared to that of the deaths because of a relatively lower proportion of people dying due to infection. 


\section{What is already known on this topic}

Several researchers have been conducting researches to estimate the economic burden and productivity losses of various diseases around the globe such as the estimation of YLLS due to COVID19 in the US[4], India[27]\& Swiss[7], DALYs due to COVID-19 in Korea[3]\& Italy[9], YPPLL due to Cancer in Brazil, Russia, India, China, and South Africa (BRICS)[40], YPPLL due to five leading causes of deaths in Iran[26], productivity loss due to Cardiovascular disease and mental illness in India[38], etc. COVID-19 has created a significant impact across the globe, some of which include 1.2 million YLLs in the US from 1 Feb 2020 to 11 July 2020[4]; 2 million YLL in India as of October 17, 2020[27]; 1.75 million YLLs due to mass confinement of 3 months in Switzerland[7]; 2531 DALYs in Korea between January 20, 2020, and April 24, 2020, with YLLs and YLDs constituting 89.7\% and 10.3\% respectively[3]; and 121449 DALYs, productivity losses of EUR 300 million and EUR 100 million due to premature mortality and absenteeism respectively, in Italy[9].

\section{What this study adds}

As is evident from this study, the disease has impacted the older population to a greater extent. The proportion of cases for the age group 65 to 70 in Kerala is only $2.11 \%$ and $2.75 \%$ of the overall cases whilst their deaths remain as high as $17.88 \%$ and $13.13 \%$. Other studies reveal a similar trend of the disease which provides strong insights for more care to be given to the elderly. Indrayan and Mishra (2020) found that the relative incidence of younger age group (<20) was only $1 / 3(12: 36) \%$ whereas those of adults aged more than 60 and between 50 to 59 were $1.5(8: 12) \%$ and 1.88 (14.5:7.7)\% respectively[27]. This trend prevails even outside the country as Garg et al (2020) concluded that out of 1482 hospitalized patients from March 1 to 28, 2020, across 14 states of the US, 3/4 were aged 50 or more[28].

The age-gender cohort-based study aims to help policymaking in terms of protecting the most vulnerable population from infection. The positive relationship between the CFR and the elderly population shows the importance to be accorded for strategies of distribution for both health infrastructure and vaccines, based on the population distribution[41]. There has been a steady drop in the CFR of Kerala since the emergence of the disease[13] though there have been multiple variants of the virus, the improvement in health infrastructure and therapeutic efforts have been able to keep the CFR abated. This would also decrease the relative contribution of YLLs to the DALYS eventually. Strategies of governance have a vital role to play in curtailing the CFR, not limited to political stability, government effectiveness, regulatory quality, control of corruption, with rule of law and voice and accountability having a negative association with the latter[41]. 
SA has been vastly adopted by researchers to depict the influence of one or more variables on the outcome(s)[3,4]. A total of 21 scenarios by adjusting six variables were analyzed in the study for 2020 and 2021 estimates. The increase in the number of deaths highly increased the DALYs whereas the reduction in life expectancy reduced the DALYs. Reducing life expectancy could be related to practical findings of researchers. The majority of the older patients have had underlying medical conditions such as pneumonia (68.8\%), hypertension (34.4\%), diabetes mellitus (50\%), and chronic obstructive airway disease (15.6\%)[42], $89.3 \%$ of the older adults (65 or more) contained comorbidities[28].

\section{Limitations of this study}

Exclusion of incidence of cases post August 20,2020, for estimation of DALYs due to unavailability of open data, has led to a certain underestimation. Also, the psychological impacts of the mitigation strategies are a potential risk that could increase mortality and are not in the scope of the present study[7]. Most of the policies have not considered mental illness and allied problems[7,43,44]. Though YLDs contribute a minor proportion in DALY, including factors such as unpaid work and presenteeism might improve the accuracy. In Kerala, about 30 and 10 percent of recovered patients have experienced post-recovery illness and long-term effects, which have not been considered in the study, resulting in an underestimation of YLDs[45]. Data on the number of deaths from Madhya Pradesh (MP), Andhra Pradesh (AP), and a part of Tamilnadu indicate that these estimates could be possible under-reporting, and this might be the case for Kerala as well [46]. The "excess deaths" approach shows a clear spike in deaths. In May 2020, MP and AP reported 34,320 and 27,100 deaths whereas the deaths in May 2021 have reached 1,64,838 and 1,20,845. Not all these could be directly attributed to COVID-19 as some relate to the deaths due to shortage of oxygen and burden on hospitals [46].

\section{CONCLUSION}

In conclusion, this is the first study to characterize the economic burden caused by COVID-19 in Kerala state using DALYS, YPPLL, and CPL. YLL contributed most to the disease burden due to COVID19. Losses due to YPPLL were reduced as the impact of COVID-19 infection was relatively lesser among the productive age groups. People aged from 40-49 years reported the highest CPL values. Decision-makers could use these estimates and aim to focus and make efforts on reducing the economic burden for the longer impact of COVID-19 in Kerala state.

The methodological framework used in this study can be applied to other states in India, and other developing countries where the disease notification data are collected by the government and are 
available in the public domain. Estimation of economic burden using DALYs, YPPLL, and CPL attributable due to COVID-19 in other states in India and developing countries could provide the basis of inter-state comparison, and prioritization of healthcare resources in resource-limited settings. Sub-group analysis would give deeper insights into the most vulnerable cohorts that require special attention to minimize the losses.

Acknowledgment: We like to sincerely thank Dr. Geetha R Menon, Scientist E, ICMR-National Institute of Medical Statistics, New Delhi for her comments towards improving this manuscript.

Contribution statement: The conception and design of the study, or acquisition of data, or analysis and interpretation of data - DJ, NMS, JM, Drafting the article or revising it critically for important intellectual content - NMS, DJ, JM, JGR, AB, Final approval of the version to be submitted - JM, DJ, $J G R, A B$

Funding: No funding support was received for this study.

Competing interests: The authors declare that they have no known competing financial interests or personal relationships that could have appeared to influence the work reported in this paper.

Patient and public involvement: Patients and/or the public were not involved in the design, or conduct, or reporting, or dissemination plans of the research.

Patient consent for publication: Not required.

Data sharing statement: All data that is incorporated into the article is available from the references mentioned. Raw data has been uploaded in the following link: https://doi.org/10.6084/m9.figshare.14999616

Ethical statement: The study has been conducted using publicly available data. No ethical approvals were sort for this study.

\section{REFERENCES}

1 Worldometer. COVID-19 Coronavirus Pandemic. 2020.

2 Laxminarayan R, Wahl B, Dudala SR, et al. Epidemiology and transmission dynamics of COVID19 in two Indian states. Science (80-) 2020;370:691-7.

3 Jo MW, Go DS, Kim R, et al. The burden of disease due to COVID-19 in Korea using disabilityadjusted life years. J Korean Med Sci 2020;35:1-10. doi:10.3346/jkms.2020.35.e199 
United States. J Public Health (Bangkok) 2020;:1-6. doi:10.1093/pubmed/fdaa159

Horton R. Offline: COVID-19 is not a pandemic. Lancet. 2020;396:874. doi:10.1016/S01406736(20)32000-6

WHO. WHO Coronavirus disease 2019 (COVID-19) Situation Report - 73. 2020;:1-13.

7 Moser DA, Glaus J, Frangou S, et al. Years of life lost due to the psychosocial consequences of COVID-19 mitigation strategies based on Swiss data. Eur Psychiatry 2020;63:1-7. doi:10.1192/j.eurpsy.2020.56

8 Neil M F, Daniel L, Gemma N-G, et al. Impact of non-pharmaceutical interventions (NPIs) to reduce COVID-19 mortality and healthcare demand. Imp Coll COVID-19 Response Team Published Online First: 2020. doi:https://doi.org/10.25561/77482

9 Nurchis MC, Pascucci D, Sapienza M, et al. Impact of the burden of COVID-19 in italy: Results of disability-adjusted life years (dalys) and productivity loss. Int J Environ Res Public Health 2020;17:1-12. doi:10.3390/ijerph17124233

Menon JC, Rakesh PS, John D, et al. What was right about Kerala's response to the COVID-19 pandemic. BMJ Glob Heal 2020;5:1-5. doi:10.1136/bmjgh-2020-003212

11 Office of the Registrar General \& Census Commissioner. Ministry of Home Affairs, Government of India. 2020.

12 Team CODD-K | covid19kerala.info. 2020.

13 C-DIT. GoK Dashboard | Official Kerala COVID-19 Statistics. 2020.

14 Aylward, Bruce (WHO); Liang W (PRC). Report of the WHO-China Joint Mission on Coronavirus Disease 2019 (COVID-19). 2020.

15 Wang H, Naghavi M, Allen C, et al. Global, regional, and national life expectancy, all-cause mortality, and cause-specific mortality for 249 causes of death, 1980-2015: a systematic analysis for the Global Burden of Disease Study 2015. Lancet 2016;388:1459-544. doi:10.1016/S0140-6736(16)31012-1

16 Salomon JA, Haagsma JA, Davis A, et al. Disability weights for the Global Burden of Disease 2013 study. Lancet Glob Heal 2015;3:e712-23. doi:10.1016/S2214-109x(15)00069-8

17 Ock M, Lee JY, Oh IH, et al. Disability weights measurement for 228 causes of disease in the Korean burden of disease study 2012. J Korean Med Sci 2016;31:S129-38. 
doi:10.3346/jkms.2016.31.S2.S129

Shanmugam KR. Discount Rate for Health Benefits and the Value of Life in India. Econ Res Int 2011;2011:1-5. doi:10.1155/2011/191425

Reserve Bank of India. Ratios and Rates. (c) Reserv. Bank India. All Rights Reserv.

Phua J, Weng L, Ling L, et al. Intensive care management of coronavirus disease 2019 (COVID19): challenges and recommendations. Lancet Respir Med 2020;8:506-17. doi:10.1016/S2213-2600(20)30161-2 Rees EM, Nightingale ES, Jafari Y, et al. COVID-19 length of hospital stay: A systematic review and data synthesis. BMC Med 2020;18. doi:10.1186/s12916-020-01726-3

22 Kerala Kaumudi Online. Govt mulls extension of retirement age as it considers deferring salary cut plan - Kerala - General. 2020.

23 ExcelNotes. Working Days in Kerala, India in 2020.

24 MOSPI. Ministry of Statistics and Program Implementation. Gov. India. 2021.http://mospi.nic.in/ (accessed 13 Mar 2021).

25 Hilderink HBM, Plasmans MHD, Snijders BEP, et al. Accounting for multimorbidity can affect the estimation of the Burden of Disease: A comparison of approaches. Arch Public Heal 2016;74. doi:10.1186/s13690-016-0147-7

26 Najafi F, Karami-Matin B, Rezaei S, et al. Productivity costs and years of potential life lost associated with five leading causes of death: Evidence from Iran (2006-2010). Med J Islam Repub Iran 2016;30:1-8.

27 Indrayan A, Mishra A. Preliminary Estimates of Years of Life Lost (YLL) Due to COVID-19 in India. medRxiv 2020;:1-10.

28 Garg S, Kim L, Whitaker M, et al. Hospitalization Rates and Characteristics of Patients Hospitalized with Laboratory-Confirmed Coronavirus Disease 2019 - COVID-NET, 14 States, March 1-30, 2020. Morb Mortal Wkly Report, US Dep Heal Hum Serv Dis Control Prev 2020;69:458-64.

29 Kirch W, editor. Human Capital Approach. Encycl. Public Heal. 2008;:697-8. doi:10.1007/9781-4020-5614-7_1583 India Development Gateway (InDG). Child Labour - Vikaspedia. 2020. 
SISA Research paper. Quantitative Skills - Consultancy for Research and Statistics. Calculating the discounted YPLL - annotated. Programmes. Fourth Edi. Oxford, United Kingdom: : Oxford University Press 2015. Hanlon P, Chadwick F, Shah A, et al. COVID-19 - exploring the implications of long-term condition type and extent of multimorbidity on years of life lost: a modelling study. Wellcome Open Res Published Online First: 2020. doi:10.12688/wellcomeopenres.15849.1

Wyper GMA, Assunção RMA, Colzani E, et al. Burden of Disease Methods: A Guide to Calculate COVID-19 Disability-Adjusted Life Years. Int J Public Health 2021;66:1-7. doi:10.3389/ijph.2021.619011

Rumisha SF, George J, Bwana VM, et al. Years of potential life lost and productivity costs due to premature mortality from six priority diseases in Tanzania, 2006-2015. PLoS One 2020;15:2006-15. doi:10.1371/journal.pone.0234300

36 Census2011. Kerala Population Sex Ratio in Kerala Literacy rate data 2011-2020.

37 Biswas S. India coronavirus: How a group of volunteers 'exposed' hidden Covid-19 deaths BBC News. BBC News Serv. 2020.

Fathima F, Kahn J, Krishnamachari S, et al. Productivity losses among individuals with common mental illness and comorbid cardiovascular disease in rural Karnataka, India. Int J Noncommunicable Dis 2019;4:86-92. doi:10.4103/jncd.jncd_17_19

39 Second wave impacted youth more: Minister - The Hindu. The Hindu. 2021.https://www.thehindu.com/news/national/kerala/second-wave-impacted-youth-moreminister/article34754237.ece (accessed 14 Jun 2021).

40 Pearce A, Sharp L, Hanly P, et al. Productivity losses due to premature mortality from cancer in Brazil, Russia, India, China, and South Africa (BRICS): A population-based comparison. Cancer Epidemiol 2018;53:27-34. doi:10.1016/j.canep.2017.12.013

41 Farzanegan MR, Feizi M, Gholipour HF. Globalization and the Outbreak of COVID-19: An Empirical Analysis. J Risk Financ Manag 2021;14:105. doi:10.3390/jrfm14030105

42 Aggarwal A, Shrivastava A, Kumar A, et al. Clinical and Epidemiological Features of SARS-CoV2 Patients in SARI Ward of a Tertiary Care Centre in New Delhi. J Assoc Physicians India 2020;68:19-26. 
43 Stark L, Ager A. A systematic review of prevalence studies of gender-based violence in complex emergencies. Trauma, Violence, Abus 2011;12:127-34.

doi:10.1177/1524838011404252

44 Rendall MS, Weden MM, Favreault MM, et al. The Protective Effect of Marriage for Survival: A Review and Update. Demography 2011;48:481-506. doi:10.1007/s13524-011-0032-5

45 The Hindu. COVID-19 | Kerala CM calls for more effective measures for containment. 2020.

46 Yadav Y. What shocking data on Covid second wave deaths really reveals: Yogendra Yadav. 2021.https://theprint.in/opinion/what-shocking-data-on-covid-second-wave-deaths-reallyreveals-yogendrayadav/678890/?fbclid=IwAR3ICQ9pYGunAmztxOtv2VUNESewRcrVckaCuH3cvYIM5keEcdEOtO 0k3LE (accessed 17 Jun 2021).

\section{Figure Captions:}

Figure 1: Sensitivity Analysis (Nov 15, 2020). A) Effect of Life Expectancy on DALYs; B) Effect of increase in cases on YLDs; C) Effect of mild cases on YLDs; D) Effect of deaths on DALYs; E) Effect of isolation after recovery on YLDs; F) DALYs for all scenarios

Figure 2: Sensitivity Analysis (June 10, 2021). A) Effect of Life Expectancy on DALYs; B) Effect of increase in cases on YLDs; C) Effect of mild cases on YLDs; D) Effect of deaths on DALYs; E) Effect of isolation after recovery on YLDs; F) DALYs for all scenarios 


\section{Figures}
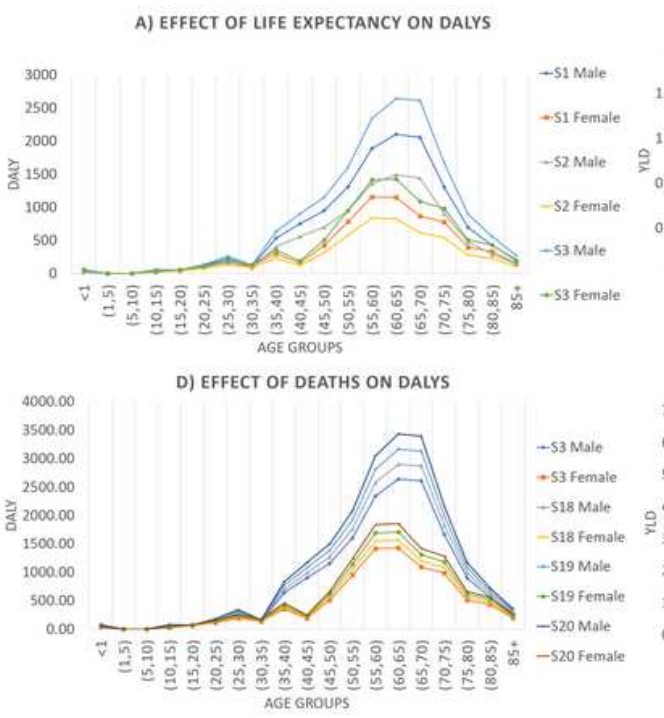

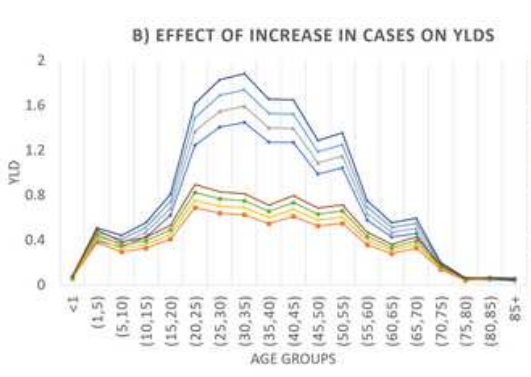

E) EFFECT OF ISOLATION AFTER RECOVERY ON YLDS

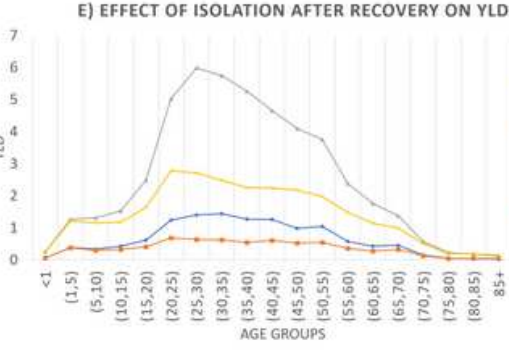

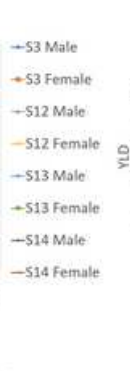

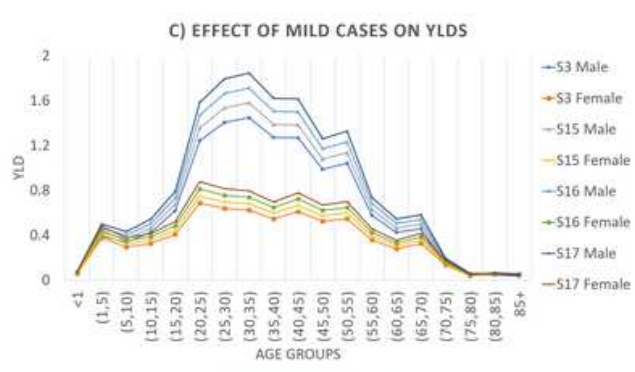

-53 Male
- $\$ 3$ female
-521 Male
-521 female
F) DALYs for all scenarios

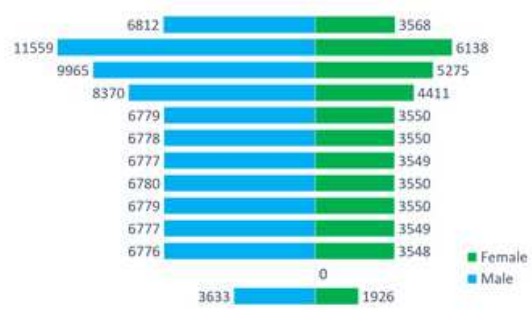

\section{Figure 1}

Sensitivity Analysis (Nov 15, 2020). A) Effect of Life Expectancy on DALYs; B) Effect of increase in cases on YLDs; C) Effect of mild cases on YLDs; D) Effect of deaths on DALYs; E) Effect of isolation after recovery on YLDs; F) DALYs for all scenarios
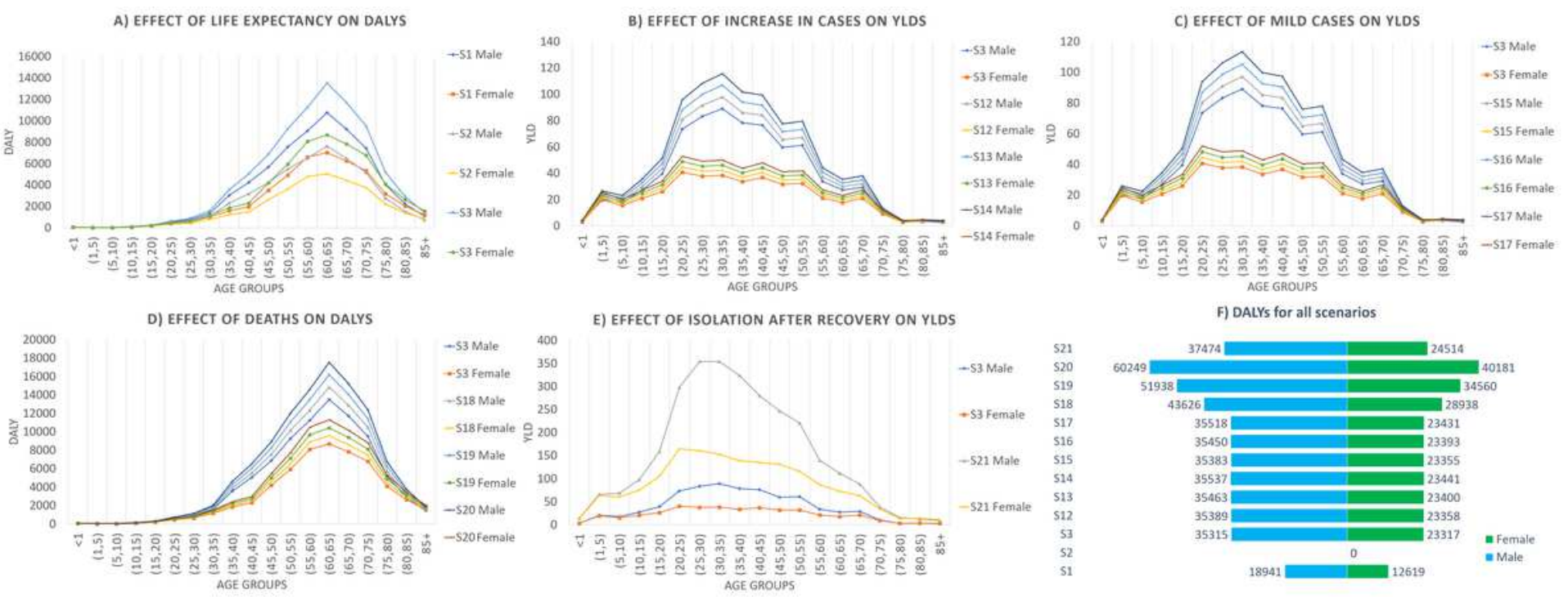

E) EFFECT OF ISOLATION AFTER RECOVERY ON YLDS
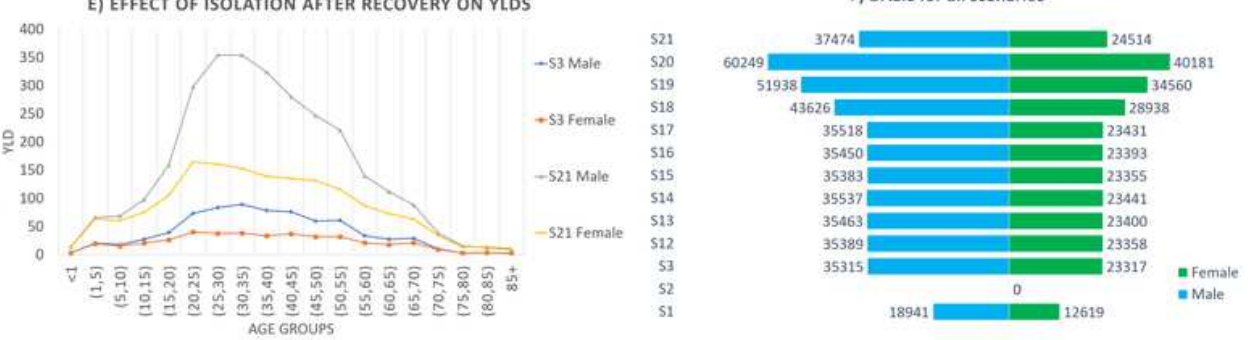

Figure 2

Sensitivity Analysis (June 10, 2021). A) Effect of Life Expectancy on DALYs; B) Effect of increase in cases on YLDs; C) Effect of mild cases on YLDs; D) Effect of deaths on DALYs; E) Effect of isolation after recovery on YLDs; F) DALYs for all scenarios

\section{Supplementary Files}


This is a list of supplementary files associated with this preprint. Click to download.

- s4.png

- s1.png

- s2.png

- s3.png

- SupplementaryTables.docx 